\title{
Dos arquivos da perseguição às histórias dos mártires: hagiografia, memória e propaganda na África romana
}

From the archives of persecution to the stories of martyrs: hagiography, memory and propaganda in Roman North Africa

\section{Julio Cesar MAGALHÃES DE OLIVEIRA•}

Resumo: A passagem dos atos e das paixões dos mártires, escritos no calor das perseguições, às narrativas martirológicas mais legendárias e épicas, que se difundem a partir do final do século IV e do início do século $\mathrm{V}$, foi muitas vezes vista, pelos historiadores, como uma das mais marcantes transformações da hagiografia na Antiguidade Tardia. Contudo, o uso dos registros dos processos judiciais para a redação tanto das tradicionais atas dos mártires como para essas novas narrativas mais extensas e épicas continuou sendo altamente valorizado pelos cristãos do Norte da África, tanto católicos como donatistas, ao menos até o começo do século V. O objetivo deste artigo é investigar as razões desse apreço pelos documentos de arquivo, sobretudo oficiais, e os diferentes usos práticos que deles fizeram os cristãos africanos, do século III ao início do século $\mathrm{V}$.

Palavras-chave: Hagiografia; Donatismo; Processos judiciais; Arquivos públicos; África Romana.

Abstract: The series of events stemming from the acts and passions of the Christian martyrs, written in the heat of persecution up to the more legendary and epic stories spreading from the late $4^{\text {th }}$ and early $5^{\text {th }}$ centuries has often been viewed by historians as one of the more striking transitions of hagiography in Late Antiquity. Nevertheless, the use of the judicial processes in the writing of the traditional martyrs' acts as well as in the composition of the more extensive and epic narratives remained highly valued in the minds of North African Christians, Donatists and Catholics alike, at least until the beginning of the $5^{\text {th }}$ century. The purpose of this paper is to understand the reasons for the high regard in which the documents in the archives were held, especially the official ones, and to research the different, practical uses made from them by North-African Christians, from the $3^{\text {rd }}$ to the beginning of the $5^{\text {th }}$ century.

Keywords: Hagiography; Donatism; Judicial processes; Public archives,; Roman North Africa.

Dos caminhos percorridos pela hagiografia cristã na Antiguidade, aquele que certamente mais chamou a atenção dos historiadores foi a passagem das primeiras histórias dos mártires, escritas no calor da perseguição, às narrativas martirológicas épicas ou legendárias, que se difundiram a partir do final do século IV e do início do século V. As razões dessa mudança de estilo, bem como do êxito que alcançaram esses novos gêneros literários na Antiguidade Tardia, já foram objeto de interpretações divergentes, sendo atribuídas tanto ao caráter supostamente "popularesco" dessa literatura (como lamentava Hippolyte Delehaye [1921] no início do século XX), como às preocupações e necessidades das lideranças eclesiásticas que começavam a controlar e organizar o culto dos santos (como propôs mais recentemente Peter Brown [1981]). No entanto, como Boudewijn Dehandschutter (1995) e outros têm insistido, é preciso lembrar que os textos antigos como os novos atendiam a necessidades muito semelhantes. Nesse sentido, como Marc Van

\footnotetext{
- Professor Doutor - Departamento de História - UEL - Univ. Estadual de Londrina - Rodovia Celso Garcia Cid, PR 445, CEP: 86051-980, Londrina, Paraná, Brasil. E-mail: jcmo@uel.br
} 
Uytfanghe (2003) ressaltou recentemente, toda a produção hagiográfica, do século III ao século V, poderia ser vista, em seu contexto de produção específico, como uma literatura comunitária e eclesial, que se desenvolve de maneira espontânea em resposta ao meio e às circunstâncias, sem que isso implique necessariamente uma concessão ao gosto popular ou a obediência ao plano prévio e sistemático de um "empresário".

O caráter espontâneo e comunitário da primeira literatura martirológica não precisa ser demonstrado. É sabido que essas primeiras narrativas surgiram da especial veneração devotada pelas comunidades cristãs a seus "mortos especiais". Como nos revelam muitos desses escritos, são mesmo as diversas igrejas locais que parecem ter encomendado a um ou mais de seus membros a redação de narrativas sobre a confissão e a morte desses seus filhos ilustres que haviam derramado seu sangue proclamando sua fé. Esses textos eram compostos a partir dos relatos das testemunhas oculares, dos escritos dos próprios mártires ou do processo-verbal de sua condenação, conservado nos arquivos públicos. Uma vez redigidos, eles eram recebidos pela comunidade eclesial para a qual haviam sido preparados e passavam a fazer parte de seus arquivos oficiais, podendo ser, posteriormente, copiados e difundidos pelos interessados. Desse modo, muitas igrejas locais passaram, progressivamente, a incorporar em seus arquivos as paixões e os atos de mártires de outras regiões, paralelamente aos de seus próprios santos, dando início à formação de coletâneas que, embora pequenas, prenunciavam o desenvolvimento futuro dos passionários e dos legendários medievais (VAN UYTFANGHE, 2003, p.202-204).

O objetivo dessas composições, pelo menos até a vitória de Constantino e o advento da Paz da Igreja, em 312-313, não era apenas o de preservar a memória dos mártires. É verdade que, mesmo os textos mais antigos, como a Paixão de Perpétua e Felicidade, na África do início do século III, já tinham em vista a posteridade e previam, no próprio texto, sua leitura anual junto às sepulturas dos mártires comemorados ${ }^{1}$. No entanto, enquanto duraram as perseguições, esse dever de memória sempre foi, ao mesmo tempo, uma forma de encorajamento e exortação a outros mártires potenciais. Na segunda metade do século III, a veneração pelos santos mártires já havia começado a ser organizada por bispos como Cipriano de Cartago, mas é apenas no século IV, com o fim das perseguições, que o culto dos mártires passa a direcionar e a impregnar a piedade cristã, levando ao desenvolvimento de verdadeiras festas nos seus aniversários e à posterior translação de suas relíquias. É assim que se desenvolve uma eloquência sacra ligada à comemoração dos mártires, com as homilias pronunciadas pelos bispos por ocasião de suas festividades, e é também nesse contexto que tem início a profusão das narrativas martirológicas “épicas”, mais ou menos legendárias, que se difundem a partir do final do século IV (VAN UYTFANGHE, 2003, p.206-207).

Essas novas narrativas, nas quais os autores não hesitavam em dar livre curso a uma imaginação edificante, não visavam apenas exaltar os feitos dos santos, através de cenas sangrentas 
de tortura ou de intervenções miraculosas, que sublinhavam seu caráter sobre-humano e seu poder como intercessores. Elas vinham também completar a escassez (lamentada por Santo Agostinho em um sermão) dos textos mais antigos, redigidos a partir de documentos de arquivo ou de testemunhos oculares (AGOSTINHO, Sermo 315, 1). Nesse sentido, essas novas narrativas não deixavam de ter o mesmo caráter comunitário e eclesial da literatura predecedente. No entanto, no exato momento em que esses novos gêneros hagiográficos começavam a se difundir, Agostinho, na África, recusava-se terminantemente a assumir a tarefa que lhe propunha um diácono italiano, Paulino de Milão, de redigir novos Atos dos mártires, sem dispor, para isso, de documentos oficiais ou de testemunhos originais. Em uma de suas cartas novas, publicada por Johannes Divjak em 1981 e datada provavelmente de 412, Agostinho expunha, nestes termos, as razões dessa recusa:

\begin{abstract}
Quemadmodum obtemperem uoluntati tuae de rebus gestis martyrum nostro sermone digerendis, cum maxime cupiam, nondum colligo. Legi enim quod dignatus es mittere et inueni quaedam aliorum sermone narrata, quaedam uero solis forensibus gestis quae me maxime delectauerunt expressa. Proinde si illa, in quibus nos alii praecesserunt, post ipse narrare uoluero, quasi doctor importunus uidebor uel superfluus operator; si autem illa quae solis gestis forensibus $<$ continetur > loquendo commemorare uoluero, uereor ne non solum non adiunem germaniorem affectum quem mihi ipsi fecerunt, cum a me sola ipsa gesta legerentur [...] (AGOSTINHO, Ep. 29*, 1, ed. DIVJAK, 1981, p.137).
\end{abstract}

Ainda que muito deseje atender à tua vontade de ver escritas com minhas palavras as gestas dos mártires, não sei como poderei fazê-lo. Li os exemplares que te dignaste enviar-me; encontrei alguns redigidos na prosa de outras pessoas, e ainda outros redigidos a partir apenas das atas forenses (solis forensibus gestis), que me deleitaram de modo especial. Por isso, se quisesse narrar de novo o que escreveram nossos predecessores, pareceria ser um professor importuno ou alguém que trabalha em vão. Se, ao contrário, quisesse recordar com minhas palavras o que só se encontra nas atas forenses (solis gestis forensibus), temo que não ajudaria a produzir o mesmo sentimento de autenticidade (germaniorem affectum) que eu mesmo senti quando li suas histórias unicamente nessas atas [...] (Tradução nossa).

Agostinho demonstrava, assim, um apreço particular pelas narrativas martirológicas redigidas a partir do processo verbal das audiências, reproduzindo o diálogo entre o juiz e o acusado, das quais o exemplo mais conhecido são os Acta proconsularia Cypriani (as Atas do martírio de São Cipriano), aliás mencionados mais à frente nessa mesma epístula pelo bispo de Hipona. Em um estudo recente, Claude Lepelley (2009) associou a atitude expressa por Agostinho nessa carta a uma posição de princípios intelectuais e teológicos que o isolava da tendência geral de sua época. Porém, comentando em 1999 a publicação por Paolo Chiesa de novos Atos autênticos de mártires africanos da perseguição de Diocleciano, Lepelley (1999, p.206) colocava essa mesma atitude em um contexto mais amplo, ressaltando uma particularidade africana para a qual eu também gostaria de chamar a atenção neste artigo. Há, de fato, muitos indícios de que o apreço de Agostinho pelos Atos 
dos mártires redigidos a partir dos processos conservados nos arquivos públicos fosse amplamente difundido na África. É o que parece indicar, por exemplo, o bom número desses textos que chegaram até nós, à diferença das narrativas hagiográficas romanceadas ou legendárias, que são muito mais raras para os mártires africanos (Cf. SAXER, 1994). Além disso, há que se ressaltar que mesmo os autores mais tardios e polêmicos, como é o caso do redator donatista da Paixão dos mártires de Abitina, ao qual retornaremos, por mais vazão que dessem à sua retórica, não deixavam de assegurar a seus leitores (ou ouvintes) que estavam redigindo seus textos ex actis publicis, "a partir dos documentos públicos" ${ }^{\prime 2}$. Neste artigo, eu gostaria de investigar as razões desse apreço pelos documentos de arquivo, sobretudo oficiais, e os diferentes usos práticos que deles fizeram os cristãos africanos, do século III ao início do século V.

Comecemos por dois episódios passados durante a Grande perseguição de Diocleciano de 303 a 305, tal como são narrados em dois textos hagiográficos africanos de natureza bastante diversa. O primeiro episódio se passa em 31 de maio de 303, durante o julgamento, em Thimida Regia, na África Proconsular, de um grupo de 27 cristãos aprisionados pelos magistrados locais e conduzidos ao tribunal do procônsul Anulino, então estabelecido na cidade, por terem sido detidos em flagrante delito de celebração do culto dominical, em desrespeito aos editos imperiais. Tratava-se de um grupo de cristãos vindos de fora, certamente de origem rural, que contavam com a hostilidade decidida não apenas das autoridades locais, mas também de parte da população da cidade que os denunciava como "magos”. O líder dessa confraria, Galônio, não era nem bispo, nem padre, nem diácono, mas possivelmente simples leitor. Talvez por isso, após ser interrogado sobre o delito de reunião, Galônio é instado, nestes termos, pelo procônsul Anulino a entregar as escrituras que se encontravam em sua possessão:

Proconsul Gallonio dixit: "Ergo et scripturae diuinae sunt penes te?". Gallonius respondit: "Etiam". Proconsul dixit: "Prode eas, ut secundum sacram iussionem comburantur". Gallonius respondit: "Non licet mihi prodere sacram et diuinam". Proconsul dixit: "In eculeo suspendatur". Cumque suspenderetur, proconsul dixit: "Vbi sunt scripturae nefariae?". Gallonius respondit: "Absconsi illas ubi nemo scit nisi solus ego". Proconsul dixit: "Vexate illum ungulis". Cumque uexaretur, respondit: "Christe, tibi gratias ago". Proconsul dixit: "In tormerntis morieris, nisi confessus fueris". Gallonius respondit: "Pro domino meo Iesu Christo libenter patior. Ipsius enim uincula latronem liber < auerunt $>$ ". Proconsul dixit: "Dicat quod uerum est." Cumque eum ungulis raderent, dixit: "Deo gratias". Proconsul dixit: "Parcite ei". Cumque ei parcerent, dixit proconsul: "Vnde huc uenisti?". Gallonius respondit: "A ciuitate Nazareth". Proconsul dixit: "Vbi est Nazareth? In qua regione?". Gallonius respondit: "In oriente". Proconsul dixit ceteris christianis: "Vos unde estis? Vbi habetis domicilia?". Responderunt: "In Nazareth". Proconsul dixit: "Sed uos, qui Afri estis, quomodo potuistis scire Nazareth?”. Responderunt: "Omnis christianus Nazareus est". Proconsul dixit: "Vbi uos nati estis?". Responderunt: "In Cellas Abaratias". Proconsul Gallonio dixi: "Ceteri unde sunt?". Gallonius respondit: "Ex locis diuersis, alii aliunde". Proconsul dixit: "Dic: ubi habes scripturas absconditas?". 
Gallonius respondit: "Abscondi illas ubi nemo scit". Proconsul dixit: "Maiora tormenta te expectant, nisi dixeris". Gallonius respondit: "In secreto loco eas habeo, id est in caelis illas praemisi". Proconsul dixit: "Potes afferre eas?". Gallonius respondit: "Eo, sed ad dominum meum". Proconsul dixit: "Dic potius ubi sunt, et parcam corpori tuo". Gallonius respondit: "Tu mihi parce". Proconsul dixit: "Si mihi dixeris, parcam". Gallonius respondit: "In caelis". Proconsul dixit: "Tantum temporis consumptum morieris, nisi confessus fueris". Gallonius respondit: "Quod uult Christus, hoc sit (Acta Gallonii, 9-31, ed. CHIESA, 1996, p.265-266).

O procônsul disse a Galônio: 'Então, estás também de posse de escrituras divinas?' Galônio respondeu: 'Sim'. O procônsul disse: 'Entrega-nas, para que, de acordo com as ordens imperiais, sejam queimadas'. Galônio respondeu: 'Não posso entregar o que é sagrado e divino'. O procônsul disse: 'Suspendam-no no cavalete'. Quando foi suspenso, o procônsul disse: 'Onde estão as escrituras abomináveis?'. Galônio respondeu: 'Estão escondidas onde só eu sei'. O procônsul disse: 'Torturem-no com unhas (de ferro)'. Durante a tortura, respondeu: 'Ah, Cristo, eu te dou graças!'. O procônsul disse: 'Morrerás nesses tormentos, se não confessares!'. Galônio respondeu: 'Padeço de bom grado por meu senhor Jesus Cristo! Pois seus laços libertaram o bandido (?)'. O procônsul disse: 'Diz a verdade!'. E enquanto era cortado pelas unhas (de ferro), disse: 'Graças a Deus!' O procônsul disse: 'Basta!' Interrompida a tortura, o procônsul diz: 'De onde vieste?' Galônio respondeu: 'Da cidade de Nazaré'. O procônsul disse: 'Onde fica Nazaré? Em qual região?' Galônio respondeu: 'No oriente'. O procônsul disse aos outros cristãos: 'De onde sois? Onde está vossa residência?' Responderam: 'Em Nazaré!' O procônsul disse: 'Mas vós, que sois africanos, como pudestes conhecer Nazaré?' Responderam: 'Todo cristão é um nazareu!' O procônsul disse: 'Onde nascestes?' Responderam: 'Em Celas Abaratias [sc. uma aldeia]' O procônsul disse a Galônio: 'E os outros, de onde são?' Galônio respondeu: 'De lugares diversos: uns de um lugar, outros de outro.' O procônsul disse: 'Diz: onde escondeste as escrituras?' Galônio respondeu: 'Eu as escondi onde ninguém mais sabe'. O procônsul disse: 'Podes mostrá-las?' Galônio disse: 'Não posso'. O procônsul disse: 'Diz: onde estão?' Galônio respondeu: 'Prefiro morrer do que dizer'. O procônsul disse: 'Tormentos muito maiores te esperam, se não disseres'. Galônio respondeu: 'Eu as tenho em um lugar secreto, isto é, eu as enviei para os céus.' O procônsul disse: 'Podes trazê-las de lá?'. Galônio disse: 'Vou, mas para o meu Senhor.' [Quiproquó: O procônsul confunde a pronúncia por Galônio de in caelis com uma referência ao vilarejo de Celas Abaratias]. O procônsul disse: 'Diz ao menos onde estão e pouparei o teu corpo'. Galônio disse: 'Tu me pouparás?' O procônsul disse: 'Se me disseres, eu te pouparei'. Galônio disse: 'No céu'. O procônsul disse: 'Quanto tempo perdido! Morrerás, se não confessares!' Galônio respondeu: 'Como Cristo quiser, assim será' (Tradução nossa).

O segundo episódio se passa em 12 de fevereiro de 304, durante o julgamento, agora em Cartago, de um grupo de 49 cristãos aprisionados por ordem dos magistrados de Abitina, na África Proconsular, e conduzidos ao tribunal do procônsul Anulino, acusados do mesmo delito de reunião para o culto dominical. O grupo, desta vez, era liderado por um padre, chamado Saturnino, e, entre seus membros, estava mesmo um decurião de Cartago, Dativo, acusado no processo de raptar uma jovem cartaginesa de dignidade senatorial. Na narrativa desse episódio, os mártires são apresentados como soldados que lutam em uma série de combates singulares. É assim, durante o 
interrogatório, sob tortura, do decurião Dativo, que o presbítero Saturnino é convocado para o julgamento:

Eius cum latera duri trucesque carnifices, magistra crudelitate monstrante, aduncis ungulis raderent, Saturninus presbyter ad proelium postulatur, quique caelestis regni contemplatione considerans parua admodum ac leuia suos commartyres sustinere, congredi etiam ipse taliter coepit. Nam dicente proconsule: Tu contra iussionem Imperatorum et Caesarum fecisti, ut hos omnes colligeres, respondit presbyter Saturninus, Domini Spiritu suggerente: Securi Dominicum celebrauimus. Proconsul ait: Quare? Respondit: Qua non potest intermitti Dominicum. Qui mox ut haec dixit, contra Datiuum statim iubetur aptari. Spectabat interea Datiuus lanienam corporis sui potius quam dolebat: et cuius ad Dominum mens animusque pendebat, nihil dolorem corporis aestimabat, sed tantum ad Dominum precabatur dicens: Subueni, rogo, Christe, habe pietatem. Serua animam meam, custodi spiritum meum, ut non confundar. Rogo Christe, da suferentiam. Cui cum a proconsule diceretur: Ex hac splendidissima ciuitate magis debueras alios ad bonam mentem uocare, et non contra praeceptum Imperatorum et Caesarum facere, fortius atque constantius acclamabat: Christianus sum. Qua uoce diabolus superatus: Parce, inquit. Simulque illum in carcerem trudens, passioni condignae martyrem reseruauit (Passio Datiui, Saturnini presbyteri et aliorum, 10, ed. MAIER, 1987, p.72).

Enquanto os duros e ferozes carrascos, tendo a crueldade como mestra, dilaceravam seu dorso (isto é, de Dativo) com as curvas unhas (de ferro), o presbítero Saturnino é chamado para o combate. Ele que, pela contemplação do reino celeste, considerava poucos e leves os suplícios que seus colegas de martírio haviam suportado, começou do mesmo modo a suportá-los. Então, quando o procônsul disse: 'Agiste contra o mandato dos imperadores e césares, reunindo todos estes', o presbítero Saturnino respondeu, inspirado pelo Espírito do Senhor: 'Celebramos tranquilamente o dia do Senhor'. O procônsul disse: 'Por quê?' E ele respondeu: 'Porque a celebração do dia do Senhor não pode ser interrompida'. Assim que ouviu isso, (o procônsul) ordenou que o atassem para tortura diante de Dativo. Enquanto isso, Dativo mais assistia do que sofria a carniceria que era feita de seu próprio corpo: tendo voltado sua mente e sua alma para o Senhor, não fazia conta de nenhuma dor corporal, mas apenas rogava ao Senhor dizendo: 'Socorreme, eu te peço, ó Cristo, tem piedade de mim! Conserva minha alma, guarda meu espírito, para que eu não seja confundido! Eu te peço, ó Cristo, dá-me força para sofrer!' Em seguida, o procônsul lhe disse: 'Nesta que é a mais esplêndida cidade, eras tu, mais do que ninguém, quem deverias chamar os outros à razão, não descumprir os mandatos dos imperadores e césares!' Dativo, porém, com mais força e constância clamava: 'Eu sou cristão!' Com essas palavras, o diabo é vencido: 'Basta!', disse o procônsul. E imediatamente o enviou para o cárcere, reservando para o mártir o martírio que ele havia merecido (Tradução nossa).

O primeiro dos documentos aqui apresentados é um dos melhores exemplos daquilo que os estudiosos da hagiografia antiga convencionaram chamar, desde o trabalho pioneiro de Dom Thierry Ruinart, no século XVII, de acta sincera, atas autênticas dos mártires redigidas quase exclusivamente a partir da transcrição dos processos verbais oficiais (RUINART, 1689). Trata-se, neste caso, de um texto descoberto em 1997 por Paolo Chiesa em um passionário latino do século XIII proveniente da biblioteca capitular de Aquileia e conservado no seminário de Gorizia, no 
Friuli, no norte da Itália (CHIESA, 1996). Como Claude Lepelley (1999, p.206-209) e Serge Lancel (1999, p.1014-1018) ressaltaram em estudos deste texto, as Atas de são Galônio e seus companheiros são tão próximas do processo verbal original que é difícil encontrar algum elemento, mesmo mínimo, de reescritura pelos cristãos, pelo menos no que concerne à sua primeira parte (a segunda parte narra, de maneira muito menos precisa, o destino de Galônio, após a morte de seus companheiros, até a cidade de Útina, onde seria executado). Como nota Claude Lepelley (inédito), pode-se mesmo observar, nessa primeira parte, a precisão das formalidades jurídicas dos processos nos tribunais romanos: nota-se, assim, sucessivamente, a função das autoridades municipais, que procedem à acusação e à instrução do processo, a do escrivão oficial, que constitui e apresenta os documentos, e a do conselho dos juristas, que assiste o procônsul. A decisão do juiz é, primeiro, apresentada em uma sententia, uma decisão fundamentada no direito e assessorada pelo conselho, e, em seguida, em um decretum, no qual a condenação é pronunciada pelo governador em sua condição de único detentor do ius gladii, o poder de condenar à morte. O próprio desenrolar da audiência revela a mistura de formalismo e de calculada crueldade que caracterizava habitualmente um tribunal romano. O diálogo entre o procônsul Anulino e o mártir Galônio é marcado pela vontade do primeiro de fazer cumprir escrupulosamente os mandatos imperiais, submetendo ocasionalmente o acusado à tortura, mas sem excessos, e pela resistência do segundo, feita de heroismo e provocação, e ainda assim, perfeitamente humana. Mesmo a expressão de mau humor e impaciência de Anulino pelo tempo perdido com um réu impertinente e irredutível como Galônio mostra-nos uma personalidade bastante diferente da imagem do perseguidor sanguinário e possesso com a qual a literatura hagiográfica posterior acostumaria associar seu nome (LANCEL, 1999, p.1016).

O segundo documento, ao contrário, é um texto de natureza bastante diversa, que já revela algumas das características mais marcantes das narrativas martirológicas "épicas" que se desenvolveram entre o final do século IV e o início do século V: aqui, o procônsul Anulino é representado como um juiz sanguinário e colérico, as torturas são exageradas ao extremo, inflingidas sem mesura e aplicadas indistintamente aos acusados e os mártires são apresentados como impassíveis mesmo diante dos maiores tormentos. Como ressaltou recentemente Alan Dearn (2004), tal como nos foi transmitida, a Paixão dos mártires de Abitina parece mesmo ter sido obra de um autor do início do século $\mathrm{V}$, que buscava entre os mártires do passado uma maneira de legitimar as posições de seu partido no presente. Seu autor era declaradamente um "donatista", ou seja, um membro da facção cristã africana surgida no início do século IV a partir da oposição à eleição de Ceciliano como bispo de Cartago, então acusado de colaboração com as autoridades pagãs durante a perseguição. Embora os "cecilianistas", partidários de Ceciliano, tivessem sido reconhecidos por Constantino como os verdadeiros "católicos", seus adversários, os "donatistas", 
liderados por Donato de Cartago, acabariam por constituir, ao longo do século IV, uma Igreja sólida e, em algumas regiões, até mesmo majoritária, até sua supressão autoritária pelo poder imperial após a grande Conferência entre os dois episcopados africanos realizada em Cartago, em 411 (cf. SHAW, 1992). Escrevendo após essa Conferência e talvez em resposta a ela, o autor da Paixão dos mártires de Abitina lançava contra Ceciliano a acusação de não apenas ter sido um traditor ordenado por traditores (isto é, um colaborador ordenado por colaboradores), mas também de ter se oposto à ajuda prestada pelos fiéis aos mártires na prisão, condenando-os à morte por inanição. A Paixão se inicia com um prefácio polêmico ( $\S 1-2)$, no qual o autor afirma escrever sua história "a partir dos registros públicos", afim de mostrar as razões da guerra que opunha a Igreja dos mártires à Igreja dos traditores. Segue-se uma segunda introdução precisando as condições da prisão dos cristãos em Abitina e de seu envio para o julgamento do procônsul Anulino em Cartago (§§ 2-4). O centro da narrativa é constituído pelo interrogatório, sob tortura, de diversos mártires, que saem vitoriosos de todos os combates e são enviados à prisão (§§ 5-18). Na conclusão, o clímax polêmico do texto, o bispo Mensúrio e seu então diácono Ceciliano são acusados de impedir os fiéis de Cartago de ajudar os confessores presos e recebem, em resposta, a sua condenação ( $§$ 20-23).

A Paixão dos mártires de Abitina foi quase sempre vista como um texto "católico" redigido no início do século IV e sucessivamente interpolado por autores "donatistas". Paul Monceaux (1920, p.53-59), Pio Franchi de’ Cavalieri (1935) e, mais recentemente, Victor Saxer (1994, p.62), reconheceram os traços "épicos" dessa narrativa como indícios de uma escrita mais tardia, mas julgavam as acusações pessoais feitas a Mensúrio e Ceciliano como pouco prováveis em uma época muito posterior à morte desses personagens. Em um estudo recente, entretanto, Alan Dearn sugeriu, de maneira convincente, que são precisamente essas acusações de responsabilidade pela morte dos mártires, até então ausentes da polêmica entre católicos e donatistas, que nos permitem ver nesse texto uma obra escrita após a Conferência de 411. A ausência de inscrições comemorativas mencionando em conjunto os nomes dos 49 mártires listados na Paixão parece também sugerir que esses nomes só foram reunidos em um único grupo de mártires pelo autor desse texto - o que explicaria sua vaga menção à morte dos mártires “em diversos lugares e em momentos diferentes” (DEARN, 2004).

Apesar disso, parece mesmo que o autor donatista havia se utilizado de documentos anteriores. Afinal, que um grupo de cristãos, presos pelo delito de reunião tivessem sido julgados em 12 de fevereiro de 304, é confirmado pela menção de Agostinho à utilização na Conferência de 411 de atas dos mártires datadas desse dia $^{3}$. Os nomes dos magistrados municipais mencionados na Paixão dos mártires de Abitina e a acusação de rapto feita ao decurião Dativo pelo advogado de uma família senatorial cartaginesa também parecem pouco prováveis de terem sido completamente inventados. É verdade que a tortura infligida a um decurião parece um exagero pouco, conforme à 
permanência dos privilégios jurídicos dos honestiores nessa época, mas o escândalo provocado pelo atentado à honra de uma família senatorial, como notou Claude Lepelley (1981, p.38-39), é uma explicação suficiente para a suspensão desse privilégio. Daí, aliás, todo o peso da repreensão do procônsul a Dativo por ter faltado às suas responsabilidades como membro do corpo dirigente de Cartago. Parece, portanto, que o autor donatista dispunha efetivamente das atas de um processo real e, por mais que a fraseologia jurídica tenha desaparecido sob sua retórica polêmica e apologética, é ainda o desenrolar da audiência que serve de núcleo à sua narrativa.

A primeira razão para o uso recorrente pelos antigos cristãos das atas de processos judiciais para a redação de histórias tão diferentes, como são os Atos de são Galônio e a Paixão dos mártires de Abitina, é precisamente a dramaticidade inerente ao espetáculo de um julgamento em um tribunal romano, que constituía em si mesma um óbvio núcleo narrativo. Como Brent Shaw (2003) já salientou, os julgamentos, as torturas e as punições conduzidos pelos governadores romanos eram verdadeiros espetáculos, ao mesmo tempo dramáticos e aterradores, deliberadamente concebidos para causar um impacto duradouro entre os espectadores. Realizados nas basílicas judiciárias ou no próprio fórum de uma capital de província ou de uma das cidades nas quais o governador estabelecia seu tribunal, os julgamentos sempre contavam com a presença de multidões de pessoas, muitas vezes mencionadas nas próprias histórias dos mártires (e.g. Acta proconsularia Cypriani, 3, 1; 5, 1). O impacto causado nos súditos do Império por esses espetáculos judiciais pode ser medido pelas múltiplas referências de bispos, como Agostinho aos temores de seus fiéis de se verem envolvidos em um processo e, ainda mais, pelos recorrentes sonhos e visões sobre os tormentos de um tribunal, tantas vezes mencionados nos textos antigos (e. g. AGOSTINHO, Sermo 308, 5). Para os cristãos que vivenciaram a perseguição, o espetáculo de um tribunal podia ser ressignificado como um combate travado entre as testemunhas de Cristo e o demônio. Mas é precisamente o registro desses julgamentos nas atas oficiais o que permitia, a partir desse espetáculo momentâneo, a constituição social de uma memória. Daí, como bem notou Brent Shaw, o temor expresso por muitos cristãos em suas histórias dos mártires de que os processos não fossem registrados ou de que seus registros fossem apagados pelas autoridades pagãs (SHAW, 2003, p.554-555).

Esse temor era certamente real, mas o registro dos processos, desde sua instrução pelas autoridades municipais até o julgamento no tribunal dos governadores, não podia ser abandonado pelos detentores da autoridade romana. Isso porque, se a brutalidade dos julgamentos e das punições era calculada para servir como um espetáculo preventivo, o formalismo de todo o processo era o que garantia a sua legalidade. Como todos os atos públicos ou privados com implicações legais, os registros dos processos criminais eram depositados em arquivos públicos, que tinham por objetivo garantir a exatidão dos documentos e sua disponibilidade a qualquer pessoa que necessitasse citálos em uma disputa (HARRIES, 1999, p.70-76). Na África romana, em particular, cada cidade devia 
dispor, em princípio, de arquivos oficiais municipais, organizados e classificados por funcionários específicos, e o mesmo pode ser dito das capitais das províncias para os arquivos da administração provincial (LEPELLEY, 1979, p.223-227). Esses arquivos eram depositados em bibliotecas públicas e, a julgar pelo que nos diz Agostinho (Contra Cresconium, III, 70), sua consulta devia ser de fácil acesso a qualquer cidadão (cf. TLILI, 2000).

O registro dos processos dos mártires cristãos, como todos os processos criminais, devia, da mesma forma, ser depositado nesses arquivos e é precisamente a exatidão garantida pela administração municipal ou provincial que suscitava o "sentimento de autenticidade" de que falava Agostinho ao ler as atas dos mártires extraídas diretamente dos arquivos públicos. A confiabilidade desses registros era, de fato, a segunda razão que havia levado os antigos cristãos a recorrerem aos arquivos da perseguição para redigirem suas histórias. Afinal, esses documentos conservavam não apenas os atos, mas também as próprias palavras dos mártires, muitas vezes tidas como pronunciadas sob inspiração do Espírito Santo. É assim que Cipriano de Cartago, no século III, interpreta as palavras pronunciadas diante do perseguidor pelos mártires de seu próprio tempo, e é do mesmo modo que o autor da Paixão dos mártires de Abitina ainda concebe a resposta do padre Saturnino ao procônsul Anulino, na passagem que já conhecemos ${ }^{4}$.

A palavra dos mártires, assim registrada, tornava-se fonte de autoridade e podia ser utilizada para legitimar diferentes posições nas disputas entre os cristãos. Na polêmica entre católicos e donatistas na África dos séculos IV e V, as concepções eclesiais e disciplinares de cada grupo levariam, muitas vezes, à elaboração de versões diferentes das mesmas histórias, sublinhando diferentes aspectos das palavras dos mártires. São bem conhecidas as supressões, acréscimos ou modificações de documentos comuns às duas Igrejas efetuadas pelos donatistas. Mas François Dolbeau mostrou, a respeito da Paixão de Lúcio e Montano, que o mesmo pode ser dito dos católicos os quais, nesse caso específico, parecem mesmo ter suprimido da história original, que os donatistas conservaram em um passionário próprio, as sentenças mais rigorosas dos mártires sobre a reintegração dos lapsi, bem como sua interferência na sucessão episcopal em Cartago, que parecia sublinhar a superioridade da autoridade do mártir sobre aquela do bispo (DOLBEAU, 1983, p. 62$65)$.

O confronto entre as duas Igrejas cristãs africanas tinha, porém, uma outra peculiaridade que explica, em grande parte, o apreço particular dos cristãos africanos pelos documentos de arquivo. Afinal, no centro da disputa estavam, precisamente, uma eleição controversa para a sede episcopal de Cartago e as diferentes atitudes adotadas na época da perseguição pelos líderes de cada um dos grupos que se defrontaram nesse processo sucessório. Por essa razão, desde muito cedo, cecilianistas e donatistas começaram a reunir documentos que provassem a inocência de seus bispos, o heroismo de seus mártires e a traição de seus adversários. O próprio imperador 
Constantino, em 314, acabaria por estimular essa atitude ao pretender resolver a disputa em um processo judicial no qual fosse comprovada, a partir dos registros da perseguição e dos testemunhos dos magistrados da época, a culpabilidade ou a inocência de um dos consagradores de Ceciliano, o bispo Félix de Abtugnos, acusado pelos partidários de Donato de Cartago de ter entregue as escrituras aos perseguidores 5 . Anos mais tarde, em um processo movido em 320 diante do governador da província, um diácono de Constantina, na Numídia, não hesitaria em utilizar os registros municipais do inquérito e do confisco dos bens da Igreja local na época da perseguição para provar a indignidade de seu próprio bispo ${ }^{6}$. Desde então, os próprios processos do reinado de Constantino, como as atas públicas da época da perseguição, passariam a fazer parte do arsenal habitual de polemistas como Optato de Mileve ou Agostinho de Hipona, para quem toda a disputa poderia ser resolvida se seus adversários donatistas aceitassem o testemunho dos acta e dos publica archiua que demonstravam a inocência de Ceciliano ${ }^{7}$.

Nesse contexto, as próprias atas dos mártires passariam a ter uma função de prova documental, inclusive para comprovar a autenticidade de outras peças utilizadas na controvérsia, mas que não podiam contar, como elas, com a mesma confiabilidade dos documentos provenientes dos arquivos públicos. É exatamente esse uso que os representantes católicos e donatistas fariam das atas dos mártires na Conferência de 411, durante as discussões sobre a autenticidade do chamado "Protocolo de Cirta". Esse debate importante foi transcrito em uma passagem das Atas da Conferência de Cartago que infelizmente se perdeu, mas que podemos conhecer a partir do elenco de temas debatidos (os capitula da Conferência) e pela versão tendenciosa que dele fez Agostinho em dois tratados escritos em 412 (o Ad donatistas post Conlationem e o Breuiculum conlationem). O "protocolo" era um documento apresentado pelos representantes católicos como prova da indignidade dos bispos donatistas que haviam condenado Ceciliano. Consistia na ata, uma reunião supostamente realizada em 5 de março de 303 em Cirta, na Numídia, entre doze bispos que se acusavam mutuamente de comprometimento durante a perseguição e mesmo de crimes de direito comum, como assassinatos. Era natural que os donatistas duvidassem da autenticidade de um documento tão comprometedor e que não havia sequer sido utilizado pelo seu maior interessado, Ceciliano. A própria datação do documento era de natureza a invalidá-lo, pois em 5 de março de 303 a perseguição não havia ainda começado na África e nenhum bispo poderia então ser acusado de colaborar com os perseguidores. Durante os debates da Conferência, os representantes donatistas parecem ter suspeitado essa incoerência e foi precisamente para tentar provar o erro da datação que eles apresentaram para a leitura suas atas dos mártires. A comparação entre a data consular dessas atas e aquela do documento em questão poderia, de fato, tê-los levado a provar a falsificação do "protocolo". Mas, preferindo atacar a inverossimilhança de uma reunião de bispos durante a perseguição, os representantes donatistas deram aos católicos a possibilidade de lhes retirar esse 
trunfo, argumentando, a partir das próprias atas dos mártires, que se elas mostravam que os cristãos podiam se reunir para o culto mesmo em épocas de perseguição, tanto mais um grupo de doze bispos poderia se reunir em uma casa privada. Desviando o foco da atenção, os católicos acabariam por manter esse documento como uma prova em sua defesa ${ }^{8}$.

Para nós, o que é mais significativo, não são os diferentes usos que católicos e donatistas fizeram das atas dos mártires na Conferência de 411, mas o fato de que ambos os grupos apresentassem os mesmos textos e neles reconhecessem uma fonte de autenticidade indiscutível. Nos anos que se seguiram à Conferência, o autor donatista da Paixão dos mártires de Abitina podia tentar reescrever o passado para confortar seus correligionários e dar sentido à experiência da dissolução autoritária da Igreja donatista. Mas dado o argumento dos católicos, de que a derrota dos donatistas se fundamentava em provas documentais, essa própria reescritura não podia ser legitimada sem a menção à utilização dos documentos de arquivo oficiais. Agostinho, por outro lado, também não hesitaria em oferecer do passado recente uma versão tendenciosa nos dois compêndios que escreveu sobre a Conferência de 411, nos quais ressaltava os fundamentos da vitória dos católicos. Mas para um bispo como ele, que durante anos e sobretudo por ocasião da Conferência havia recorrido de modo tão insistente à autenticidade dos documentos oficiais como provas irrefutáveis da justeza de sua causa, reescrever o passado com os artifícios literários de uma paixão épica dos mártires era mesmo uma atitude impensável. Ao recusar, em 412, o pedido que lhe fazia o diácono Paulino de Milão para que redigisse em sua prosa novas atas dos mártires, Agostinho podia, de fato, demonstrar uma posição de princípios intelectuais e teológicos muito particular. Mas essa é uma posição que nós podemos facilmente compreender no contexto mais amplo da autoridade atribuída à palavra registrada nos arquivos públicos e dos usos que dela fizeram em suas disputas os cristãos africanos.

\section{Agradecimentos}

Agradeço a Margarida Maria de Carvalho, pelo convite para publicar nesta revista a conferência pronunciada no XI Ciclo de Estudos Antigos e Medievais e I Encontro do Laboratório de Estudos sobre o Império Romano realizado na UNESP de Franca, em agosto de 2009. Meus agradecimentos também a Claude Lepelley, Carlos Roberto Galvão-Sobrinho e Antony Hostein, pelas referências e pela ajuda na preparação inicial deste artigo, bem como a Álvaro Bragança Jr., Jean-Michel Carrié, Pedro Paulo A. Funari e Ana Teresa M. Gonçalves, pelos comentários e sugestões feitos por ocasião do congresso de Franca. Por fim, agradeço a Priscila Rodrigues Nunes, pela leitura atenta e paciente e pelos comentários feitos à primeira versão deste texto. A responsabilidade pelas ideias aqui expostas restringe-se ao autor. 


\section{Referências Bibliográficas}

BROWN, Peter. The Cult of the Saints: Its Rise and Function in Latin Christianity. Chicago: The University of Chicago Press, 1981.

CHIESA, Paolo. Un testo agiografico africano ad Aquileia: gli Acta di Gallonio e dei martiri di Timida Regia. Analecta Bollandiana, Bruxelas, v. 114, pp. 241-268, 1996.

DEARN, Alan. The Abitinian martyrs and the outbreak of the Donatist schism. Journal of Ecclesiastical History, Cambridge, v. 55, n. 1, pp. 1-18, 2004.

DEHANDSCHUTTER, Boudewijn. Hagiographie et histoire: à propos des Actes et Passions des martyrs. In: LAMBERIGTS, M.; VAN DEUN, P. (eds.). Martyrium in Multidisciplinary Perspective. Mémorial Louis Reekmans. Leuven: Peeters Publishers, 1995, pp. 295-301.

DELEHAYE, Hippolyte. Les Passions des martyrs et les genres littéraires. Bruxelas: Société des Bollandistes, 1921.

DIVJAK, Johannes. Sancti Aurelii Augustini Opera. Epistulae ex duobus codicibus nuper in lucem prolatae (Corpus scriptorum ecclesiasticorum latinorum, 88). Viena: F. Tempsky, 1981.

DOLBEAU, François. La Passion des saints Lucius et Montanus: histoire et édition du texte. Revue d'Études Augustiniennes, Paris, v. 29, pp. 39-82, 1983.

. Augustin d'Hippone, Vingt-six sermons au peuple d'Afrique. Paris: Institut d'études augustiniennes, 1996.

. La 'Passion' des martyrs d'Abitina: remarques sur l'établissement du texte. Analecta Bollandiana, Bruxelas, v. 121, pp. 273-296, 2003.

DUVAL, Yvette. Chrétiens d'Afrique à l'aube de la paix constantinienne. Les premiers échos de la grande persécution. Paris: Institut d'études augustiniennes, 2000.

FRANCHI DE' CAVALIERI, Pio. Note agiografiche. Studi e Testi, Cidade do Vaticano, v. 65, pp. $1-71,1935$.

HARRIES, Jill. Law and Empire in Late Antiquity. Cambridge: Cambridge University Press, 1999.

LANCEL, Serge (éd). Actes de la Conférence de Carthage en 411, v. 1 (Sources chrétiennes, 194). Paris: Cerf, 1972.

- Gesta conlationis Carthaginiensis, anno 411. Accedit Sancti Augustini breuiculus conlationis cum Donatistis. (Corpus cristianorum. Series latina, 149A). Turnhout: Brepols, 1974.

1991.

. Actes de la Conférence de Carthage en 411, v.3 (Sources chrétiennes, 224). Paris: Cerf,

. Le proconsul Anullinus et la grande persécution en Afrique en 303-304 apr. J.-C.: nouveaux documents. Comptes rendus de l'Académie des inscriptions, Paris, pp. 1013-1022, 1999. 
LEPELLEY, Claude. Les cités de l'Afrique romaine au Bas-Empire, vol. 1: La permanence d'une civilisation municipale. Paris: Institut d'études augustiniennes, 1979.

. Les cités de l'Afrique romaine au Bas-Empire, vol. 2: Notices d'histoire municipale. Paris: Institut d'études augustiniennes, 1981.

. L'apport d'actes de martyrs nouvellement découverts à la connaissance de la géographie historique de l'Afrique proconsulaire. Bulletin de la Société Nationale des Antiquaires de France, Paris, pp. 205-221, 1999.

. Chrétiens et païens au temps de la persécution de Dioclétien: le cas d'Abthugni. In: ID. Aspects de l'Afrique romaine: les cités, la vie rurale, le christianisme. Bari: Edipuglia, 2001, pp. 321-328.

. Les réticences de saint Augustin face aux légendes hagiographiques d'après la lettre Divjak 29*. In: ROUSSEAU, P.; PAPOUTSAKIS, M. (eds.). Transformations of Late Antiquity: Essays for Peter Brown. Aldershot: Ashgate, 2009, pp. 147-158.

. Témoignages sur la procédure pénale dans les actes des martyrs: à propos d'une passion de martyrs africains du temps de Dioclétien récemment découverte (inédito; a ser publicado na Revue Historique de Droit Français et Étranger).

MAIER, Jean-Louis. Le Dossier du Donatisme. Vol. I: Des origines à la mort de Constance II (303361). (Texte und Untersuchungen zur Geschichte der altchristlichen Literatur, 134). Berlim: Akademie-Verlag, 1987.

MONCEAUX, Paul. Histoire littéraire de l'Afrique chrétienne depuis les origines jusqu'à l'invasion arabe, vol. 5. Paris: Ernest Leroux, 1920.

MUSURILLO, Herbert. Acts of the Christian Martyrs. Oxford: Oxford UP, 1972.

PETSCHENIG, M. Sancti Aurelii Augustini scripta contra Donatistas. Pars 3: Liber de unico baptismo, Breuiculus collationis cum Donatistis, Contra partem Donati post gesta, Sermo ad Caesariensis ecclesiam plebem, Gesta cum Emerito Donatistarum episcopo, Contra Gaudentium Donatistarum episcopum libri II. (Corpus scriptorum ecclesiasticorum latinorum, 53). Viena: F. Tempsky, 1910.

RUINART, Thierry. Acta primorum martyrum sincera. Paris: F. Muguet, 1689.

SAXER, Victor. Afrique latine. In: PHILIPPART, G. (ed.). Hagiographies. Histoire internationale de la littérature hagiographique latine et vernaculaire en Occident des origines à 1550, vol. 1. Turnhout: Brepols, 1994, pp. 25-95.

SHAW, Brent. African Christianity: disputes, definitions and "Donatists". In: GREENSHILDS, M. R.; ROBINSON, T. A. (eds.). Orthodoxy and Heresy in Religious Movements. Discipline and Dissent. Lampeter: Eldwin Millen Press, 1992, pp. 5-34.

. Judicial nightmares and Christian memory. Journal of Early Christian Studies, Baltimore, v.11, n.4, pp. 533-563, 2003. 
TLILI, Noureddine. Les bibliothèques en Afrique romaine. Dialogues d'Histoire Ancienne, Besançon, v.26, n.1, pp. 151-174, 2000.

VAN UYTFANGHE, Marc. L'hagiographie antique tardive: une littérature populaire? Antiquité Tardive, Paris, v.9, pp. 201-218, 2001.

ZIWSA, Karl. Sancti Optati Milevitani Libri VII (Corpus scriptorum ecclesiasticorum latinorum, 26). Viena: F. Tempsky, 1893.

\section{NOTAS}

1 Passio Perpetuae et Felicitatis, I, 6 (ed. MUSURILLO, 1972, p.106-108): et nos itaque quod audiuimus et contrectauimus, annuntiamus et uobis, fratres et filioli, uti et uos qui interfuistis rememoremini gloriae domini et qui nunc cognoscitis per auditum communionem habeatis cum sanctis martyribus, et per illos cum domino nostro Iesu Christo, cui est claritas et honor in saecula saeculorum. Amen.

${ }^{2}$ Passio Datiui, Saturnini presbyteri et aliorum, 1 (ed. MAIER, 1987, p.61): acta martyrum legat quae necessario in archiuo memoriae conscripta sunt ne, saeculis transeuntibus, obsolesceret et gloria martyrum et damnatio traditorum ! [...] aggredior, inquam, ex actis publicis scribere. Sobre a datação controversa desse texto, ver Dolbeau (2003) e Dearn (2004).

${ }^{3}$ Agostinho, Breuiculum conlationis, III, 17, 32 (ed. LANCEL, 1974, p.296-297): Donatistae protulerunt gesta, ubi auditi et pro confessioni passi sunt. [...] Gesta martyrum quibus ostendebatur tempus persecutionis, consulibus facta sunt Diocletiano nouies et Maximiano octies, pridie idus februarias. Cf. Passio Datiui, Saturnini et aliorum, 1 (ed. MAIER, 1987, p. 59): Incipiunt confessiones et actus martyrum Saturnini presbyteri, Datiui, Felicis, Ampelii et ceterorum infra scriptorum, qui propter collectas et scripturas dominicas sub Anolino tunc proconsule Africae die pridie idus februarii Kartagine Dominum confessi, diuersis locis temporibusque discretis beatissimum sanguinem profuderunt. François Dolbeau (2003, p. 277-283) observa, no entanto, que alguns manuscritos da Passio Saturnini apresentam na introdução a data de 18 de janeiro de 304. As duas datações implicam tradições litúrgicas diferentes, a primeira talvez preservando a memória do aniversário da audiência à qual os confessores teriam comparecido em Abitina, em 18 de janeiro, a segunda, por sua vez, a da audiência diante do procônsul em Cartago, em 12 de fevereiro.

${ }^{4}$ Passio Datiui, Saturnini presbyteri et aliorum, 10 (ed. MAIER, 1987, p.72): respondit presbyter Saturninus, Domini Spiritu suggerente. Sobre a posição de Cipriano, ver sua Ep. 10, 4, 1: Documentum rei praesens proelium praebuit. Vox plena Spiritu Sancto de martyris ore prorupuit, cum Mappalicus beatissimus inter cruciatus suos proconsuli diceret: "Videbis cras agonem". Et quod ille cum uirtutis ac fidei testimonio dixit Dominus impleuit. Cf. Cipriano, Ep. 81, 1, 2: Quodcumque enim sub ipso confessionis momento confessor episcopus loquitur aspirante Deo ore omnium loquitur.

${ }_{5}$ Acta purgationis Felicis episcopi autumnitani (ed. ZIWSA, 1893, p.197-204). Uma nova edição corrigida desse texto foi proposta por Duval (2000, p.231-244). Sobre o processo em questão, ver Lepelley (2001, p.321-328).

${ }^{6}$ Gesta apud Zenophilum consularem (ed. ZIWSA, 1893, p.185-197).

${ }^{7}$ Ver, por exemplo, Agostinho, Sermo Dolbeau 2, 22 (ed. DOLBEAU, 1996, p.343): Ego acta recito, qui fuerint traditores ostendo, ipsos sedisse contra Caecilianum innocentem qui de suis criminibus confessi sunt lego, maiores uestros priores causam Caeciliani episcopi huius urbis ad imperatorem Constantinum detulisse publica archiua proclamant.

${ }^{8}$ Gesta Conlationis Carthaginiensis anno 411, capitula, III, 407-454 (ed. LANCEL, 1991, p.525-535); Agostinho, Ad donatistas post conlationem, 14, 18 (ed. PETSCHENIG, 1910, p.97-162) e Breuiculum conlationis, III, 17, 32 (ed. LANCEL, 1974, p.296-297). Sobre as discussões a respeito da autenticidade do "Protocolo de Cirta", ver Lancel (1972, p.94-97).

Artigo recebido em 09/2009. Aprovado em 12/2009. 